\title{
Research of Multi-Process Schemes Grey Fuzzy Synthetic evaluation Method
}

\author{
Jie JIANG \\ Wuhan Polytechnic
}

\begin{abstract}
The main influencing factors on decision-making of process schemes are analyzed to set up a synthetic evaluation system involving processing quality, production cost, productivity effect and process flexibility. In view of the deficiency of traditional fuzzy synthetic evaluation, the method of qualitative index's quantification with fuzzy number is proposed. Establish the grey fuzzy synthetic evaluation model combining grey theory and fuzzy mathematics. The model here can ensure the impersonality and credit of the result, and the example proved this.
\end{abstract}

KEYWORD: Process schemes; Synthetic evaluation model; Grey theory; Fuzzy mathematics

\section{INTRODUCTION}

In the actual production process design, process design was influenced by manufacturing resources, machining method and process of part features, process design principle, can get various feasible schemes for the same machining[1]. Therefore, according to the different production requirements, manufacturing resource conditions, to conduct a comprehensive evaluation to determine the choice of process scheme.

The optimization problem of multi process scheme is a complicated issue that a combination of qualitative and quantitative, so the solution is a very complex problem, generally it is difficult to use the usual mathematical optimization method for solving. To solve this kind of problem, the fuzzy comprehensive evaluation method is effective, but the traditional fuzzy evaluation method only consider all of the factors separately on the relative membership degree of alternative contribution, for the comprehensive evaluation problem of multiple process plans, among all the factors are not independent of each other, and has some relevance, there is a kind of grey relationship. Therefore, introducting grey system theory based on the traditional fuzzy comprehensive evaluation method, forming grey fuzzy comprehensive evaluation method.

\section{ESTABLISH THE EVALUATION INDEX SYSTEM OF PROCESS SCHEMES}

Factors of affecting the process plan by the attribute is divided two levels to establish evaluation index system. The first layer is the processing quality, product cost,production efficiency, flexible process, they are the main factors to decide theprocess scheme. The second layer is the index for further evaluation and subdivision of the factor set, the following specific factors:

The processing quality: usually consists of surface roughness, dimensional tolerance and form and position tolerance, they are three important aspects of measuring the processing quality, for different products, its processing quality require different emphasis.

The products cost: including equipment cost, tooling cost, wage costs, the cost of resource consumption and production logistics cost. Production logistics is an important part of the production process, in the entire process of productionmaterials, only $5 \%$ time for processing, while the remaining $95 \%$ time in the storage, handling, transportation and processing of status, product cost and logistics related directly to $20 \% \sim 40 \%$.

Production efficiency: mainly cosider the three aspects of single piece machining time, business time and rest time. For simplicity, the single processing time includes processing time and auxiliary time. 
Process flexibility: the strain capacity of the various accidents happen in manufacturing system, by the process plan flexible decay rate to decide.

\section{GREY FUZZY COMPREHENSIVE EVALUATION MODEL}

\subsection{Qualitative index assignment}

Optimization of multi process scheme is a comprehensive evaluation includes both qualitative indicators and quantitative index. The qualitative indicators, especially the processing quality, which are difficult to put an exact figure. About this kind of index, the decision-maker need subjective judgments to fuzzy information, using natural language variables on the assignment, and the linguistic variables further transformed into fuzzy numbers corresponding to a quantitative representation[2,3].

For qualitative indicators, set $V=\left(v_{1}, v_{2}, \cdots, v_{n}\right)$ is a comment collection, $v_{i} \geq 0(i=1,2, \cdots, n)$ denote from low to high levels comments. Can define linguistic variable word $\mathrm{v}=\{$ very poor, poor ,compare poor, general, compare good ,good, very good $\}$.According to the fuzzy number definition, the natural language variable definition will be defined for fuzzy number as shown in table 1 .

Table 1. Linguistic variables and their corresponding fuzzy numbers

\begin{tabular}{|c|l|l|l|}
\hline $\begin{array}{l}\text { Serial } \\
\text { number }\end{array}$ & $\begin{array}{l}\text { Natural } \\
\text { language }\end{array}$ & $\begin{array}{l}\text { Trapezoidal } \\
\text { fuzzy number }\end{array}$ & $\begin{array}{l}\text { L-R trapezoidal } \\
\text { fuzzy number }\end{array}$ \\
\hline 1 & Very poor & $(0,0,0,0.2)$ & $(0,0 ; 0,0.2)$ \\
\hline 2 & Poor & $(0,0,0.1,0.3)$ & $(0,0.1 ; 0,0.2)$ \\
\hline 3 & $\begin{array}{l}\text { Compare } \\
\text { poor }\end{array}$ & $(0,0.2,0.2,0.4)$ & $(0.2,0.2 ; 0.2,0.2)$ \\
\hline 4 & General & $(0.3,0.5,0.5,0.7)$ & $(0.5,0.5 ; 0.2,0.2)$ \\
\hline 5 & $\begin{array}{l}\text { Commpare } \\
\text { good }\end{array}$ & $(0.6,0.8,0.8,1.0)$ & $(0.8,0.8 ; 0.2,0.2)$ \\
\hline 6 & Good & $(0.7,0.9,1.0,1.0)$ & $(0.9,1.0 ; 0.2,0)$ \\
\hline 7 & Very good & $(0.8,1.0,1.0,1.0)$ & $(1.0,1.0 ; 0.2,0)$ \\
\hline
\end{tabular}

\subsection{Concrete steps of gray fuzzy comprehensive evaluation}

In essence, a process scheme $u_{i}$ is mapping of $n$ factor index, namely $u_{i}=f_{i}\left(v_{1}, v_{2}, v_{3}, \cdots, v_{n}\right)$.

Therefore, when the factor index determining, this process scheme is also to determine. Selecting excellent process scheme is to compare each scheme of the most ideal scheme and attribute index. Based on the grey system theory and fuzzy comprehensive evaluation method, get a grey fuzzy comprehensive evaluation model. The establishment of the steps are as follows:
(1) Dtermine the involved scheme collection $U=\left\{u_{1}, u_{2}, u_{3}, \cdots, u_{m}\right\}$, namely all sorts of feasibletechnology scheme.

(2) Dtermine the influence factors collection $V=\left\{v_{1}, v_{2}, v_{3}, \cdots, v_{n}\right\}$, namely the collection of various factor to impact evaluation process scheme as elements. This paper mainly consider the processing quality, product cost, production efficiency and flexibility process four factors.

(3) Dtermine the reference index collection $V_{0}=\left\{v_{01}, v_{02}, v_{03}, \cdots, v_{0 n}\right\}$, namely best index collection. It is selected in each scheme optimal selection index from the values in the conventional numerical or ideal value as a reference index. As in the index system, an index of maximum value is good, then take the index of maximum in the program in the value of the optimal value; as in the index system, an index of the minimum value is good, then take the minimum value in the index in the schemes for the best value. The reference index set a best solution is composed of these optimal values.

(4) Index normalized index. The solution property of different general belong to different domain, in order to facilitate comparisons of each attribute, need for standardized processing to the original index, in order to ensure equivalence evaluation. Its standardized by the following formula [4]:

$\varepsilon_{i j}=\left\{\begin{array}{l}v_{i j} / v_{0 j} \\ v_{0 j} / v_{i j}\end{array}\right.$

The reference index to standared set $\varepsilon_{0}=\left[\begin{array}{lllll}1 & 1 & 1 & \cdots & 1\end{array}\right]_{1 \times n}$.

(5) Clculate the correlation coefficient [5]. The standard reference index collection $\varepsilon_{0}=\left[\begin{array}{lllll}\varepsilon_{01} & \varepsilon_{02} & \varepsilon_{03} & \cdots & \varepsilon_{0 \eta}\end{array}\right] \quad$ set $\quad$ as $\varepsilon_{i}=\left[\begin{array}{lllll}\varepsilon_{i 1} & \varepsilon_{i 2} & \varepsilon_{i 3} & \cdots & \varepsilon_{i n}\end{array}\right](i=1,2,3, \cdots m)$ the ideal scheme, as set by comparison. Correlation can be given by the following formula:

$$
\begin{aligned}
& \Delta_{i k}=\left|\varepsilon_{0 k}-\varepsilon_{i k}\right|, i=1,2, \cdots m ; k=1,2, \cdots n \\
& M=\max _{i} \max _{k} \Delta_{i k}, m=\min _{i} \min _{k} \Delta_{i k}
\end{aligned}
$$

\section{Correlation coefficient:}

$\gamma_{i k}=\frac{m+\xi M}{\Delta_{i k}+\xi M}, \xi \in(0,1)$,

$i=1,2, \cdots m, k=1,2, \cdots n$

In formula, the resolution of 0.5 or less than 0.5 is good. So can get the correlation coefficient matrix $\gamma=\left(\gamma_{i k}\right)_{m \times n}$ 。

(6) Dcision method. When compared scheme, it must be the correlation coefficient index of each scheme are integrated to a degree of association. In 
themulti-level decision, correlation by correlation coefficient multiplied by the weight is implemented, the weights may be determined using the fuzzy analytic hierarchy process. Get the degree of association of a level, and then a layer of computational relevance as the original index, the next level of repeated calculation, calculate the correlation degree until the top. The top quality order of the size of the correlations equence is scheme.

\section{USING FUZZY AHP TO DETERMINE THE WEIGHT}

In the grey fuzzy comprehensive evaluation method, the determination of the weightis very important. Because the weights determined directly affect the results of evaluation. The analytic hierarchy process (AHP) method as a combination of qualitative and quantitative, in the calculation of the weights is an effective method. But the traditional AHP, the expert constructing judgment matrix, according to the "1-9" scale to determine the importance of two between the indexes, the results of the comparison can only use a number between 1/9 and 9 between to express, no other choice. Such judgments are often not considered fuzzy judgment. In fact, people in the treatment of complicated decision-making problems, not consciously use the fuzzy judgement in the selection and judgment. AHP will be extended to fuzzy environment, to obtain the fuzzy analytic hierarchy process (FAHP) [6].

\section{APPLICATION EXAMPLES}

There are tree process scheme $P_{1}, P_{2}, P_{3}$, for a shaft parts, each process scheme contains 4 processing operation, nodes flexible annotation in a node, see figure 1. For optimization three kinds of feasible technology scheme using the fuzzy grey method, the original data as shown in table 2 .

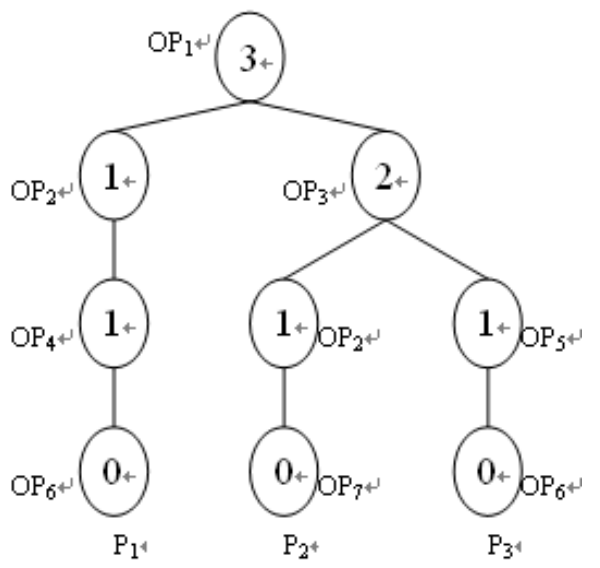

Figure 1. Shaft parts process planning tree
Calculating the flexible attenuation rate of process scheme

$$
\begin{aligned}
& P_{1}=\frac{1}{3}\left(\frac{1}{3}+\frac{1}{1}+\frac{0}{1}\right)=0.444 \\
& P_{2}=\frac{1}{3}\left(\frac{2}{3}+\frac{1}{2}+\frac{0}{1}\right)=0.389 \\
& P_{1}=\frac{1}{3}\left(\frac{2}{3}+\frac{1}{2}+\frac{0}{1}\right)=0.389
\end{aligned}
$$

\begin{tabular}{|c|c|c|c|c|}
\hline $\begin{array}{l}\text { First level } \\
\text { parameters }\end{array}$ & $\begin{array}{l}\text { Two level } \\
\text { parameters }\end{array}$ & $\begin{array}{l}\text { Scheme } \\
\mathrm{P}_{1}\end{array}$ & $\begin{array}{l}\text { Schems } \\
\mathrm{P}_{2}\end{array}$ & $\begin{array}{l}\text { Scheme } \\
\mathrm{P}_{3}\end{array}$ \\
\hline & $\begin{array}{l}\text { Surface } \\
\text { roughness }\end{array}$ & good & $\begin{array}{l}\text { compare } \\
\text { poor }\end{array}$ & general \\
\hline \multirow[t]{4}{*}{$\begin{array}{l}\text { Processing } \\
\text { quality }\end{array}$} & $\begin{array}{l}\text { Dimensional } \\
\text { tolerance }\end{array}$ & IT8 & IT9 & IT7 \\
\hline & $\begin{array}{l}\text { Shape and } \\
\text { position } \\
\text { tolerance }\end{array}$ & general & poor & good \\
\hline & $\begin{array}{l}\text { Equipment } \\
\text { cost }\end{array}$ & 2 & 5 & 1 \\
\hline & Tooling cost & 3 & 1 & 2 \\
\hline \multirow{4}{*}{$\begin{array}{l}\text { Product } \\
\text { cost }\end{array}$} & Wage cost & 40 & 50 & 30 \\
\hline & $\begin{array}{l}\text { Resource } \\
\text { consumption } \\
\text { cost }\end{array}$ & 2 & 4 & 3 \\
\hline & $\begin{array}{l}\text { Production } \\
\text { logistics cost }\end{array}$ & 10 & 8 & 6 \\
\hline & $\begin{array}{l}\text { Single piece } \\
\text { machining } \\
\text { time }\end{array}$ & 1.2 & 2 & 3 \\
\hline \multirow[t]{2}{*}{$\begin{array}{l}\text { Production } \\
\text { efficiency }\end{array}$} & $\begin{array}{l}\text { Business } \\
\text { time }\end{array}$ & 1 & 1.5 & 1.3 \\
\hline & Rest time & 1 & 2 & 3 \\
\hline $\begin{array}{l}\text { Process } \\
\text { flexibility }\end{array}$ & $\begin{array}{l}\text { Flexibility } \\
\text { attenuation } \\
\text { rate }\end{array}$ & 0.444 & 0.389 & 0.389 \\
\hline
\end{tabular}

Table 2 processing scheme data information.

For the surface roughness, dimensional tolerance, shape and position toleranceand other qualitative index, this paper use table 1 fuzzy processing to dispose, expressed by fuzzy numbers corresponding.

Each attribute index optimal values constitute a reference index collection, by using formula to standardized treatment, which involves fuzzy number division, this article uses theapproximate calculating formula of Bonissone to calculate[5]. Get each processing scheme standardization results, and compared with reference index, by the formula (2) can get second layer correlation coefficient matrix:

$\gamma_{1}=\left[\begin{array}{ccc}1 & 0.574 & 0.513 \\ 0.365 & 0.379 & 0.333 \\ 0.513 & 1 & 1\end{array}\right]$ 
$\gamma_{2}=\left[\begin{array}{ccccc}0.444 & 0.375 & 0.615 & 1 & 0.5 \\ 0.333 & 1 & 0.5 & 0.444 & 0.615 \\ 1 & 0.444 & 1 & 0.546 & 1\end{array}\right]$

$\gamma_{3}=\left[\begin{array}{ccc}1 & 1 & 1 \\ 0.455 & 0.5 & 0.4 \\ 0.357 & 0.591 & 0.333\end{array}\right]$

The second layer each factor weights can be calculated using the fuzzy analytic hierarchy process for

$W_{1}=\left[\begin{array}{lll}0.144 & 0.428 & 0.428\end{array}\right]$

$W_{2}=\left[\begin{array}{lllll}0.123 & 0.054 & 0.51 & 0.054 & 0.259\end{array}\right]$

$W_{3}=\left[\begin{array}{lll}0.6 & 0.2 & 0.2\end{array}\right]$ layer

Similarly, the weights of each factor for the first $W=\left[\begin{array}{llll}0.391 & 0.391 & 0.15 & 0.068\end{array}\right]$

Correlation coefficient matrix and the weights can be obtained using the above, and comprehensive evaluation on the second level, can get the degree of association and combined with the flexible process, which constitutes the correlation coefficient matrix for the first level

$R=\left[\begin{array}{cccc}0.609 & 0.572 & 1 & 0.333 \\ 0.357 & 0.533 & 0.453 & 1 \\ 0.93 & 0.945 & 0.399 & 1\end{array}\right]$

Therefor, this can be obtained by three kinds of feasible technology scheme compared to ideal optimal $\quad B=R \circ W^{T}=\left[\begin{array}{lll}0.634 & 0.484 & 0.861\end{array}\right]$, preferential relation three process scheme for $\mathrm{P} 3>\mathrm{P} 1>\mathrm{P} 2$.

\section{CONCLUSION}

Grey fuzzy comprehensive evaluation model built for the multi process scheme in the this paper, which can comprehensively, intuitively reflects the comprehensive performance of different process scheme, and provides a basis for optimal selection of process scheme. This method overcomes the disadvantages of fuzzy comprehensive evaluation method, using fuzzy qualitative index number to quantify, combining the fuzzy number operation, to make up for the grey system theory to index linguistic variables; weight calculation using fuzzy analytic hierarchy process, more in line with the decision maker's psychological, can to effectively reduce the information loss, thus making the optimization results more objective.

\section{REFERENCE}

[1] Cai Ze, Zhang Shusheng, Fan Haitao. The Multi-tiered Fuzzy Comprehensive Evaluation of Multiple Process Plans. Microprocessors, 2011, 32(3):65-67.

[2] Adem Golec, Esra Kahya. A fuzzy model for competencybased employee evaluation and selection. Computers \& Industrial Engineering, 2007, 52(1): 143-161.

[3] Wang Nan, Pang Bo, Liu Kaidi. The unascertained comprehensive appraisement model and its application on comprehensive evaluation of the mechanical process plans. Machinery design \& manufacture, 2013, 11:270272.

[4] Qu Fuzheng, Fei Ye, Wang Xin. Multi-attribute grey fuzzy optimal selection model of complex mechanism design scheme and its application. Journal of Dalian university of technology, 2005, 45(2): 201-205.

[5] Liu Sifeng, Dang Yaoguo, Fang Zhigeng, etc. Greysystem theory and its applications. Beijing: Science press, 2010

[6] Xiao Ciyuan. Engineering fuzzy system. Beijing: Science press, 2005. 